\title{
Article \\ Reliability Analysis of CFRP-Packaged FBG Sensors Using FMEA and FTA Techniques
}

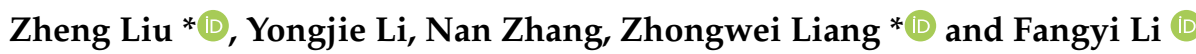 \\ School of Mechanical and Electrical Engineering, Guangzhou University, Guangzhou 510006, China; \\ a1050160337@163.com (Y.L.); z1909152666@163.com (N.Z.); lfy703@sina.com (F.L.) \\ * Correspondence: liu_best@yeah.net (Z.L.); liangzhongwei@gzhu.edu.cn (Z.L.); \\ Tel.: +86-18719470769 (Z.L.); +86-13416240167 (Z.L.)
}

check for updates

Citation: Liu, Z.; Li, Y.; Zhang, N.; Liang, Z.; Li, F. Reliability Analysis of CFRP-Packaged FBG Sensors Using FMEA and FTA Techniques. Appl. Sci. 2021, 11, 10859. https://doi.org/ 10.3390/app112210859

Academic Editors: David Ian Ellis and $\mathrm{He} \mathrm{Li}$

Received: 12 August 2021

Accepted: 9 November 2021

Published: 17 November 2021

Publisher's Note: MDPI stays neutral with regard to jurisdictional claims in published maps and institutional affiliations.

Copyright: (c) 2021 by the authors. Licensee MDPI, Basel, Switzerland. This article is an open access article distributed under the terms and conditions of the Creative Commons Attribution (CC BY) license (https:// creativecommons.org/licenses/by/ $4.0 /)$.

\begin{abstract}
Carbon fiber-reinforced plastics (CFRP)-packaged fiber Bragg grating (FBG) sensors are widely used in full-scale structural testing of wind turbine blades (WTBs). However, the specific process to make CFRP-packaged FBG sensors, such as packaging, bonding, welding, etc., are mainly manually operated, and no unified standard or rule has been formed yet. Non-standard specific processes, coupled with complex stress distribution, unstable working environments, etc., result in the CFRP-packaged FBG sensors having various failures with time, resulting in inaccurate measurements. Thus, the need to carry out related failure analysis is urgent. This paper therefore performed a reliability analysis for CFRP-packaged FBG sensors using failure mode and effects analysis (FMEA) and fault tree analysis (FTA) techniques. The results provide an important basis towards analyzing performance degradation and functional failures for CFRP-packaged FBG sensors.
\end{abstract}

Keywords: reliability analysis; CFRP-packaged FBG sensors; FMEA; FTA

\section{Introduction}

As one of the most common renewables, wind-generated electricity has increasingly received great interest abroad. The wind turbine blade (WTB) is the key part of the wind turbine, and its quality and reliability are the basis of the system's safe and stable operation [1,2]. WTB full-scale structural testing (see Figure 1) is a commonly used method to check the design and manufacture of a new blade before delivery [3,4]. In WTB full-scale structural testing, comparison of the measured strain of the blade surface and its theoretical value is the basis on which to judge whether the blade fails or not; thus, an accurate strain measurement is required. Currently, gauges are often used to measure strain in WTB structural testing (see Figure 2), where their extra wiring, heavy accumulated weight, and high failure rates have brought about inconvenience for long-term monitoring. Considering this situation, FBG sensors are applied in WTB full-scale structural testing due to their light weight, anti-electromagnetic interference, anti-corrosion properties, and their ease of setup. FBG sensors are usually packaged with carbon fiber-reinforced plastics (CFRP) before use (see Figure 3) because the FBG sensors are thin and easy to break and CFRP has a good compatibility with the blade surface's material $[5,6]$.

Due to working conditions, complicated alternating loads, and other uncertain factors, the packaged FBG sensors will be subject to performance degradation and function failures as time goes on. Wen et al. [7] found that the metallized FBG sensors have obvious attenuation of temperature sensitivity, spectral characteristics, and experience power failure in short-time high temperature testing, which indicates that a degradation of spectral and reflection peak power in the FBG sensors exists. Liu [8] studied the fatigue characteristics of adhesive-packaged FBG sensors by a series of tests, and found that the sensitivity, repeatability, and consistency of the adhesive-packaged FBG sensors degenerated after a period of vibration. Zhang [9] studied the strain transfer characteristics of the FBG sensor by establishing a strain transfer mechanical model, analyzed the influences of the 
bonding layer on the average strain transfer ratio of the FBG sensor, and verified that the deterioration of the bonding layer would cause the degradation of the strain transfer ratio. According to the literature, the quality and performance of packaged FBG sensors are not stable in practice; consequently, the reliability analysis of FBG-packaged sensors is very important. Our previous study [10] showed that the bonding layer greatly affects the strain transfer ratio of the CFRP-packaged FBG sensors applied in WTB full-scale structural testing, and the reliability of the CFRP-packaged FBG sensors are influenced by adhesive types, adhesive thickness, etc. However, the study only considered the influence of the bonding layer, and ignored the influences of the packaged layer, welding quality, inherent reliability of FBG sensors, etc. Consequently, the measurement accuracy and long-term availability of the CFRP-packaged FBG sensors still cannot be ensured, and a much more in-depth reliability analysis is needed. Among all reliability analysis methods, the failure mode and effects analysis (FMEA) and fault tree analysis (FTA) techniques are commonly used. FMEA is a systemic process to ascertain critical failure items, such as the failure modes, failure causes, failure effects, etc., and it adopts the risk priority number (RPN) to assess the risk of one failure item [11-14]. FTA is a deductive process to determine the root causes of a failure item, and the results can show how different component failures or certain working conditions can combine together to cause failure [15-17]. Currently, the FMEA and FTA techniques have been widely applied to engineering for their wellestablished and well-understood features, and their effectiveness in improving system reliability and availability has been proven [18-21]. In this regard, based on the need for an in-depth reliability analysis for CFRP-packaged FBG sensors, this paper will study the reliability and availability of CFRP-packaged FBG sensors applied in WTB full-scale structural testing by using the FMEA and FTA techniques, and provide the foundation for analyzing performance degradation and functional failures in CFRP-packaged FBG sensors.

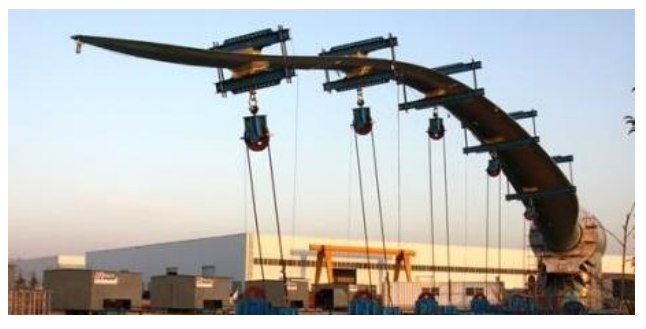

(a)

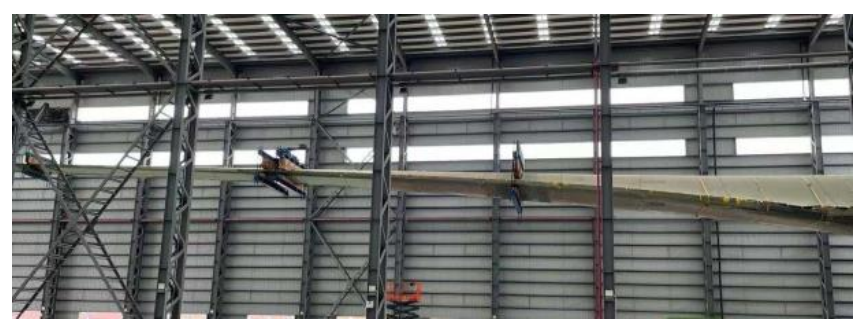

(b)

Figure 1. WTB full-scale structural testing: (a) static testing; (b) fatigue testing.

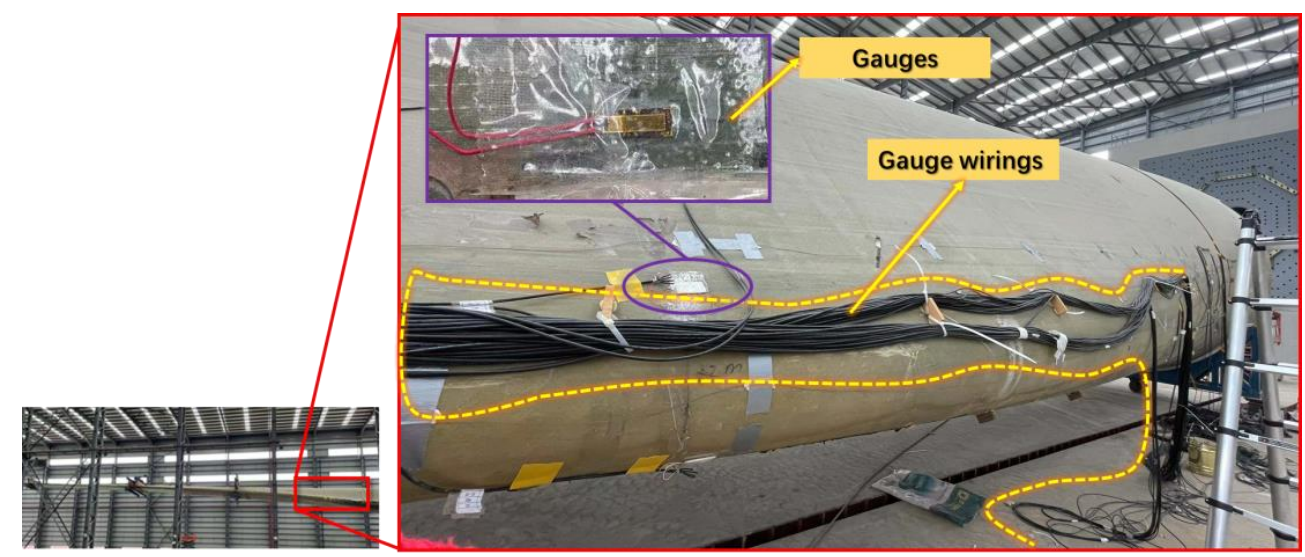

Figure 2. Gauge and gauge wirings in WTB full-scale structural testing. 


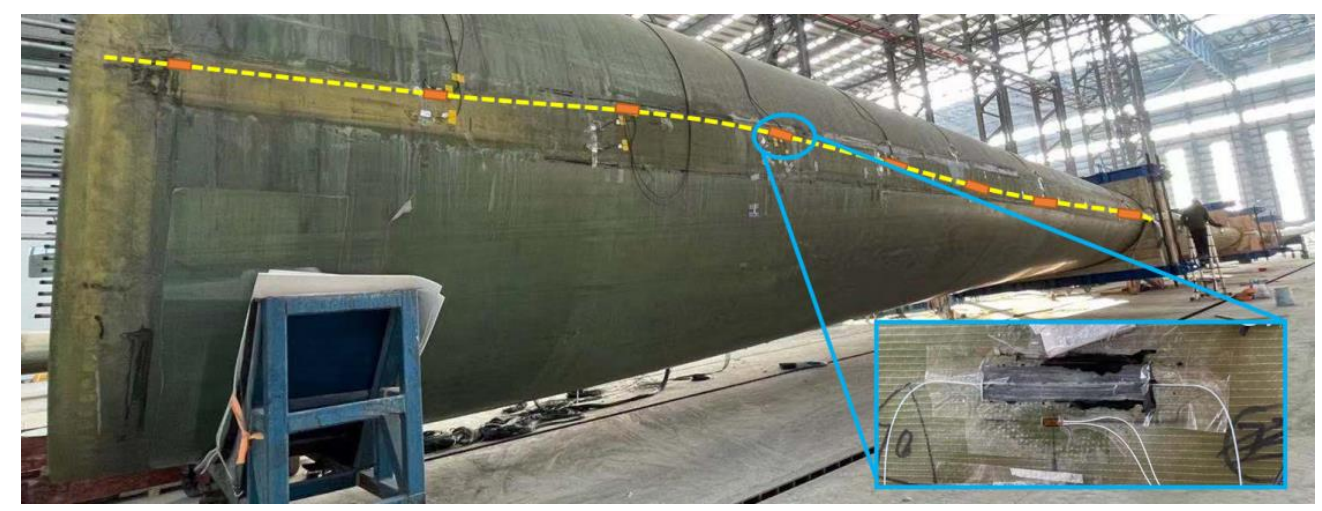

Figure 3. CFPP-packaged FBG sensors in WTB full-scale structural testing.

The remainder of this paper is organized as follows. In Section 2, the principle of the FBG sensor and the structure of CFRP-packaged FBG sensors are briefly introduced. In Section 3, reliability analysis of CFRP-packaged FBG sensors using the FMEA technique is conducted, the failure modes of CFRP-packaged FBG sensors as well as the causes are ascertained, the effects of the failure modes are analyzed, and the RPN of each failure item is calculated. Based on FMEA, three key faults with a higher RPN share are further analyzed using the fault tree analysis (FTA) technique in Section 4, the minimum cut set of each key fault is determined, and the failure probability as well as the property weightiness is calculated. In Section 5, the conclusions are established.

\section{The principle and structure of CFRP-packaged FBG sensors}

\subsection{The Principle of the FBG Sensor}

The FBG sensor is a type of optical fiber sensor whose refractive index changes periodically along the fiber axis, and its structure is composed of cladding, grating, and optical fiber (see Figure 4). When broadband light passes through the FBG sensor, the incident light spectrum whose wavelength meets the fiber Bragg reflection condition will be reflected, and the rest will be transmitted through, from the other end of the fiber core $[22,23]$.

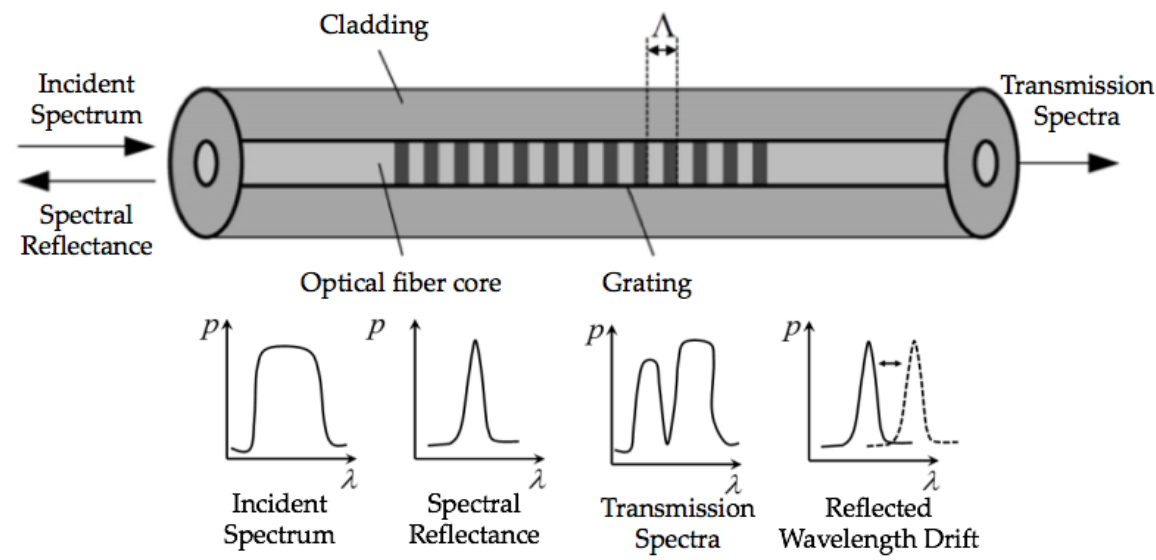

Figure 4. The structure of FBG sensors.

The wavelength of the light spectrum that satisfies the reflection condition can be written as follows:

$$
\lambda_{B}=2 n_{e f f} \Lambda
$$

where $\lambda_{B}$ is the center wavelength of the FBG sensor, $n_{\text {eff }}$ is the effective refractive index, and $\Lambda$ is the length of the period. When the stress to which the FBG sensor is subjected changes, the length of period $\Lambda$ as well as the refractive index $n_{e f f}$ will change, resulting 
in a change in the center wavelength $\lambda_{B}$. By measuring the center wavelength $\lambda_{B}$ before and after external stress is applied, the unknown physical quantity being measured can be obtained. However, when the FBG sensors are packaged by CFRP and pasted on the blade surface, the stress to which the FBG sensor is subjected will be influenced by the packaging layer and bonding layer, and the effective refractive index $n_{\text {eff }}$ and the length of the period $\Lambda$ will not be equal to the original ones. Moreover, if the packaging layer and bonding layer are damaged or degraded, the measurement accuracy cannot be assured.

\subsection{The Structure of CFRP-packaged FBG Sensors Used in WTB Full-Scale Structural Testing}

A CFRP-packaged FBG sensor is a kind of "sandwich" structure, which mainly includes (see Figure 5): FBG sensor (FBG), CFRP packaging layer (PL), and bonding layer (BL). The PL is used to protect the FBG sensor, which contains a layer of carbon fiber placed above the FBG sensor and another two layers placed below. The BL is used to bond the CFRP-packaged FBG sensor to the blade surface. A certain number of CFRP-packaged FBG sensors are series linked by connecting components (CC), and finally connected to the FBG demodulator (FBG-D).

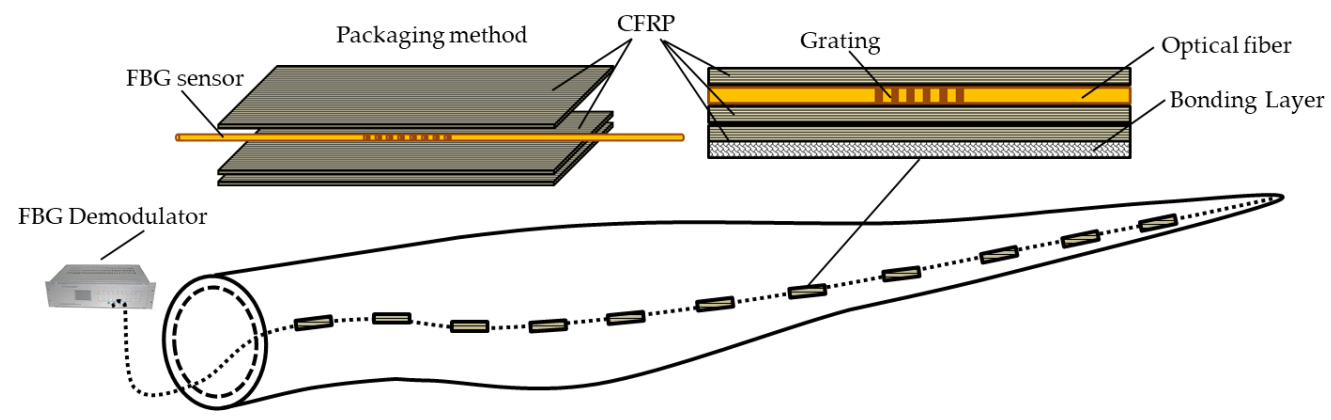

Figure 5. The structure of CFRP-packaged FBG sensors and their application on a WTB.

The strain transfer process of the CFRP-packaged FBG sensor is shown in Figure 6. In particular, the axial strain of the blade surface occurs under the action of external load, and in turn, it transfers from the blade surface to the bonding layer, the packaging layer, and the FBG sensor by shear force, and then the optical fiber generates axial strain, which causes the wavelength of the grating to change [24].

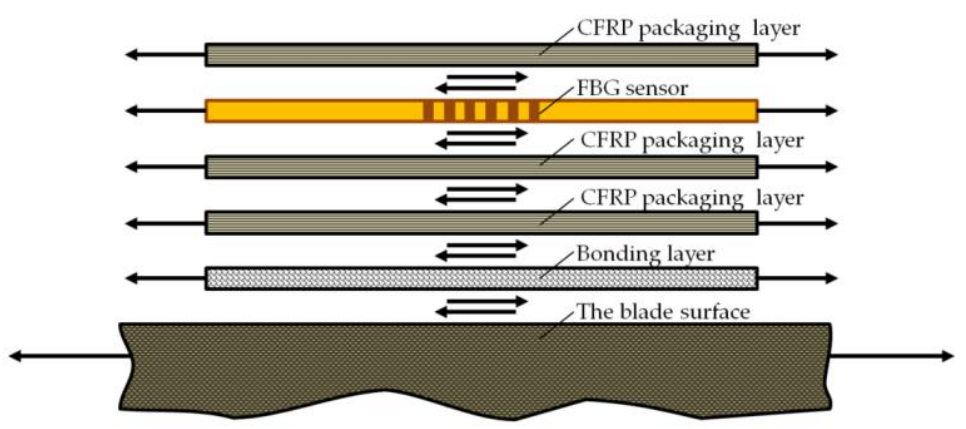

Figure 6. Strain transfer process of a CFRP-packaged FBG sensor.

\section{Reliability Analysis of CFRP-Packaged FBG Sensors Using the FMEA Technique}

\subsection{A Brief Introduction of the FMEA Technique}

FMEA is a systemic process to ascertain critical failure items, and the results can show the failure modes, failure causes, as well as their related components or subsystems. The FMEA method is a bottom-up analysis program and its analysis flow is shown in Figure 7. For more information about FMEA, please refer to [11-14,18-20]. 


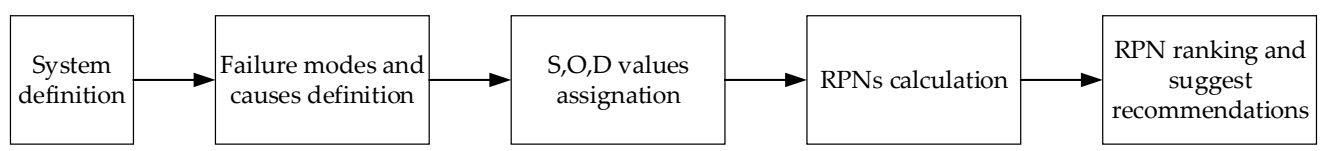

Figure 7. Flow chart of failure mode and effects analysis.

FMEA adopts the risk priority number (RPN): the product of three indices: severity $(\mathrm{S})$, occurrence $(\mathrm{O})$, and detection $(\mathrm{D})$, to assess the risk of one certain failure item, where severity represents the consequence of a failure, occurrence denotes a failure's likelihood, and detection reflects the ability of a failure to be observed.

In engineering projects, the RPNs can be calculated by [20]:

$$
\mathrm{RPN}=\mathrm{A}(\mathrm{S}) \times \mathrm{A}(\mathrm{O}) \times \mathrm{A}(\mathrm{D})
$$

where $A(S), A(O)$, and $A(D)$ are the average values of severity, occurrence, and detection given by the specialists.

\subsection{FMEA of CFRP-Packaged FBG Sensors}

Due to the harsh working conditions and long-periodic alternating load, the CFRPpackaged FBG sensors will be subjected to various failures in the process of WTB full-scale structural testing. On the basis of the failure data of the CFRP-packaged FBG sensors collected in the WTB full-scale structural testing, the failure modes, failure causes, and failure effects of the CFRP-packaged FBG sensors are analyzed, and the FMEA table is produced. In order to rank the relative importance of the failure modes and failure causes, components of the CFRP-packaged FBG sensors, namely the severity (S), occurrence $(\mathrm{O})$, and detection (D) of each failure item, are assessed by eight specialists with diverse backgrounds (Table 1 ). The rating scales of the severity $(\mathrm{S})$, occurrence $(\mathrm{O})$, and detection (D) refer to the standards that have been commonly used in FMEAs of electronic component or composite-composed systems (Table 2). The FMEA of the CFRP-packaged FBG sensor is shown in Table 3.

Table 1. Specialists involved in failure analysis of the CFRP-packaged FBG sensors.

\begin{tabular}{cccc}
\hline Code & Employer & Duty & Working Period \\
\hline 1 & Wind Energy Company & Quality Engineer & 8 Years \\
2 & Wind Energy Company & Test engineer & 6 Years \\
3 & Wind Energy Company & Test engineer & 5 Years \\
4 & FBG sensor Company & Components Design & 14 Years \\
5 & FBG sensor Company & Quality Engineer & 5 Years \\
6 & University & Researcher & 8 Years \\
7 & University & Researcher & 8 Years \\
8 & University & Researcher & 4 Years \\
\hline
\end{tabular}

Table 2. Rating scales of S, O, and D of FMEA of the CFRP-packaged FBG sensors.

\begin{tabular}{cccc}
\hline Rating & Severity (S) & Occurrence (O) & Detection (D) \\
\hline 1 & Effect is not noticed & Extremely less & Certain \\
2 & Very slight effect & Remote & Very high \\
3 & Slight effect causing annoyance & Very slight & High \\
4 & Slight effect causing return of product & Slight & Moderate \\
5 & Moderate effect causing return of product & Occasional & Medium \\
6 & Significant effect & Moderate & Low chance \\
7 & Major effect & Frequent & Slight \\
8 & Extreme effect, system inoperable & High & Remote \\
9 & Critical effect, system shutdown & Very high & Very remote \\
10 & Hazardous, without warning & Extremely high & No inspection \\
\hline
\end{tabular}


Table 3. Failure modes and their causes and effects on the CFRP-packaged FBG sensor.

\begin{tabular}{|c|c|c|c|c|c|c|c|c|c|}
\hline \multicolumn{4}{|c|}{ Failure Mode Level } & \multicolumn{2}{|r|}{ Failure Cause Level } & \multicolumn{4}{|c|}{ RPN Level } \\
\hline System & Code of FM & Failure Modes & Failure Effects & Code & Failure Causes & $\mathrm{A}(\mathrm{S})$ & $\mathrm{A}(\mathrm{O})$ & $A(D)$ & RPNs \\
\hline \multirow[t]{10}{*}{ FBG } & FM1 & Grating broken & Unusable FBG sensor & $\# 1$ & Rough construction & 8 & 2 & 3 & 48 \\
\hline & FM2 & Sidelobe interference & Multiple peaks & $\# 2$ & Excessive splicing loss & 8 & 3 & 4 & 96 \\
\hline & & & & \#3 & Packaging process errors & 8 & 3 & 4 & 96 \\
\hline & FM3 & No output & Unusable FBG sensor & $\# 4$ & $\begin{array}{l}\text { Small turning radius of the } \\
\text { ending grating }\end{array}$ & 9 & 1 & 4 & 36 \\
\hline & FM4 & Misinformation & $\begin{array}{c}\text { Inaccurate } \\
\text { measurement results }\end{array}$ & $\# 5$ & Unstable supply voltage & 6 & 5 & 3 & 90 \\
\hline & & & & \#6 & $\begin{array}{l}\text { Dust existing in the transmitter } \\
\text { or receiver }\end{array}$ & 6 & 1 & 3 & 18 \\
\hline & & & & $\# 7$ & $\begin{array}{l}\text { Insufficient transmitter or } \\
\text { receiver power }\end{array}$ & 6 & 3 & 3 & 54 \\
\hline & FM5 & Signal drift & Unusable FBG sensors & $\# 8$ & Jamming external environment & 8 & 4 & 3 & 96 \\
\hline & FM6 & Discontinuous signals & Unusable FBG sensors & $\# 9$ & Jamming external environment & 8 & 3 & 3 & 72 \\
\hline & FM7 & $\begin{array}{l}\text { Decreased strain } \\
\text { transfer rate }\end{array}$ & $\begin{array}{c}\text { Inaccurate } \\
\text { measurement results }\end{array}$ & $\# 10$ & $\begin{array}{l}\text { Changed bonding parameters or } \\
\text { packaging parameters }\end{array}$ & 8 & 4 & 7 & 224 \\
\hline \multirow[t]{6}{*}{ PL } & FM8 & Delamination & $\begin{array}{l}\text { Decreasing compressive } \\
\text { strength and buckling } \\
\text { limit }\end{array}$ & $\# 11$ & Under impact force & 6 & 4 & 4 & 96 \\
\hline & & & & $\# 12$ & $\begin{array}{l}\text { Interlamination Stress between resin } \\
\text { and prepreg }\end{array}$ & 6 & 3 & 4 & 72 \\
\hline & FM9 & Cracking & $\begin{array}{c}\text { Inaccurate strain } \\
\text { measurement results } \\
\text { and reduced service life }\end{array}$ & $\# 13$ & $\begin{array}{l}\text { Single direction of carbon } \\
\text { fiber prepreg }\end{array}$ & 6 & 1 & 3 & 18 \\
\hline & & & & $\# 14$ & $\begin{array}{l}\text { Stress concentration at the } \\
\text { changing section }\end{array}$ & 6 & 2 & 3 & 36 \\
\hline & FM10 & Buckling & $\begin{array}{l}\text { Material deformation } \\
\text { and inaccurate strain } \\
\text { measurement results }\end{array}$ & $\# 15$ & $\begin{array}{l}\text { Excessive temperature and pressure } \\
\text { during packaging }\end{array}$ & 6 & 3 & 4 & 72 \\
\hline & & & & $\# 16$ & Asymmetric CFRP layers & 6 & 3 & 4 & 72 \\
\hline
\end{tabular}


Table 3. Cont.

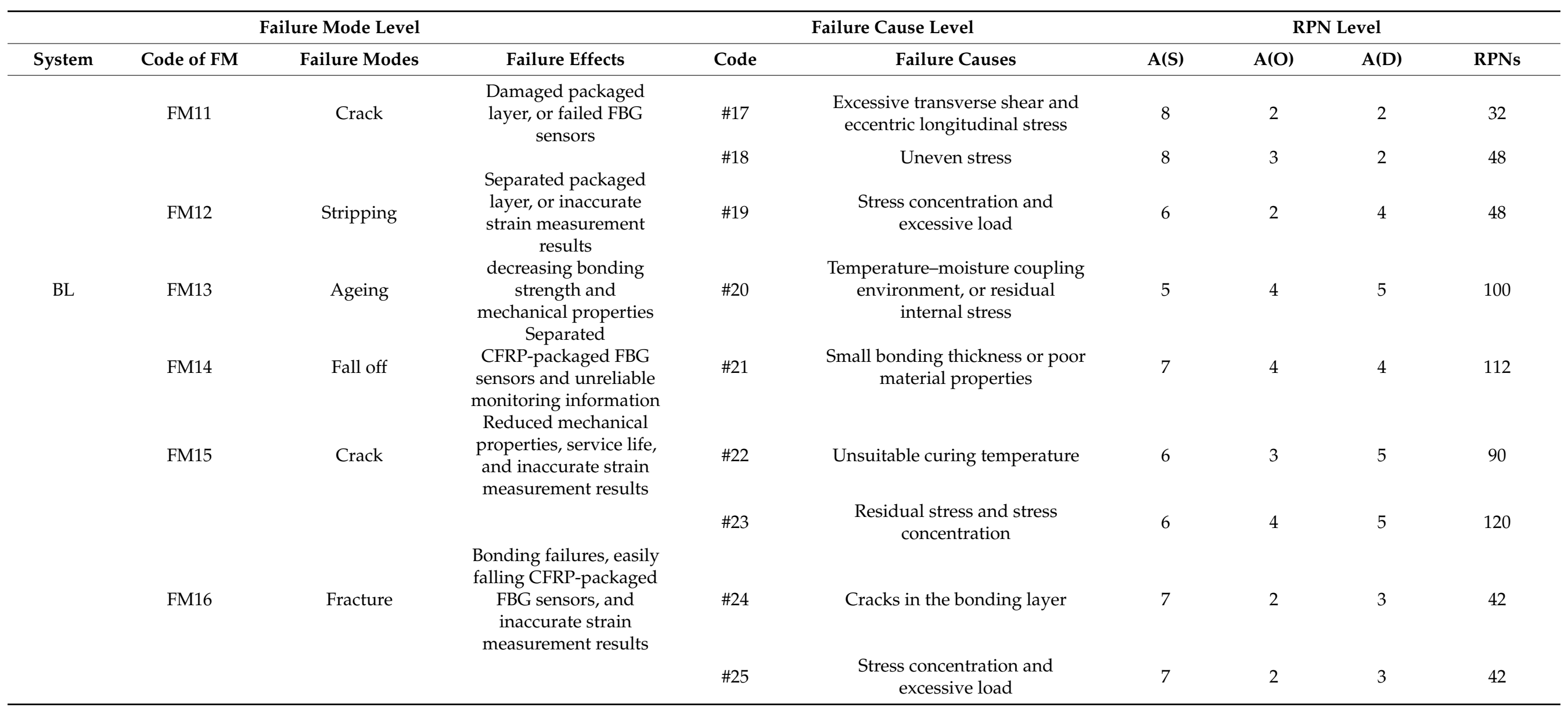


Table 3. Cont.

\begin{tabular}{|c|c|c|c|c|c|c|c|c|c|}
\hline \multicolumn{4}{|c|}{ Failure Mode Level } & \multicolumn{2}{|r|}{ Failure Cause Level } & \multicolumn{4}{|c|}{ RPN Level } \\
\hline System & Code of FM & Failure Modes & Failure Effects & Code & Failure Causes & $\mathrm{A}(\mathrm{S})$ & $\mathrm{A}(\mathrm{O})$ & $\mathrm{A}(\mathrm{D})$ & RPNs \\
\hline \multirow[t]{4}{*}{$\mathrm{CC}$} & \multirow[t]{2}{*}{ FM17 } & \multirow[t]{2}{*}{ Power loss } & $\begin{array}{l}\text { Reduced transmission } \\
\text { distance, abnormal data } \\
\text { transmission, and } \\
\text { inaccurate strain } \\
\text { measurement results }\end{array}$ & \#26 & $\begin{array}{l}\text { Bad welding process, or mismatch } \\
\text { structure parameters }\end{array}$ & 6 & 3 & 5 & 90 \\
\hline & & & & \#27 & $\begin{array}{c}\text { Fiber bending loss, Rayleigh } \\
\text { scattering loss, or light wave } \\
\text { absorption loss }\end{array}$ & 6 & 4 & 5 & 120 \\
\hline & FM18 & Fiber broken & Unusable FBG sensors & \#28 & Over bending of optical fiber & 9 & 2 & 3 & 54 \\
\hline & \multirow{3}{*}{ FM19 } & \multirow{3}{*}{ Work failure } & \multirow{3}{*}{$\begin{array}{l}\text { Failed signal and data } \\
\text { acquisition }\end{array}$} & $\# 29$ & $\begin{array}{l}\text { Stress concentration and excessive } \\
\text { load }\end{array}$ & 9 & 3 & 3 & 81 \\
\hline \multirow[t]{2}{*}{ FBG-D } & & & & $\# 30$ & $\begin{array}{l}\text { Abnormal external factors and } \\
\text { internal quality defects }\end{array}$ & 8 & 1 & 3 & 24 \\
\hline & & & & \#31 & Improper human operation & 8 & 1 & 3 & 24 \\
\hline
\end{tabular}

$\mathrm{A}(\mathrm{S}), \mathrm{A}(\mathrm{O})$, and $\mathrm{A}(\mathrm{D})$ are the average values of severity, occurrence, and detection of the employed specialists. 


\subsection{Results and Discussion}

Under the coupling influence of harsh working conditions and long-periodic alternating load, the CFRP-packaged FBG sensors showed a variety of failure modes. By evaluating the severity $(\mathrm{S})$, occurrence $(\mathrm{O})$, and detection $(\mathrm{D})$, the RPNs of the 31 failure modes can be obtained (Table 3). In order to provide more information for operation and maintenance of the CFRP-packaged FBG sensors, the relative importance of the three indices is compared by computing their proportionalities in the RPN of each failure mode (Figure 8). From Figure 8, we can infer that most failure modes of the CFRP-packaged FBG sensor happen slightly or occasionally. Once the CFRP-packaged FBG sensor is in fault, the measurement accuracy cannot be ensured. Fortunately, most failure modes are easily detected; thus, periodical inspection and maintenance are essential.

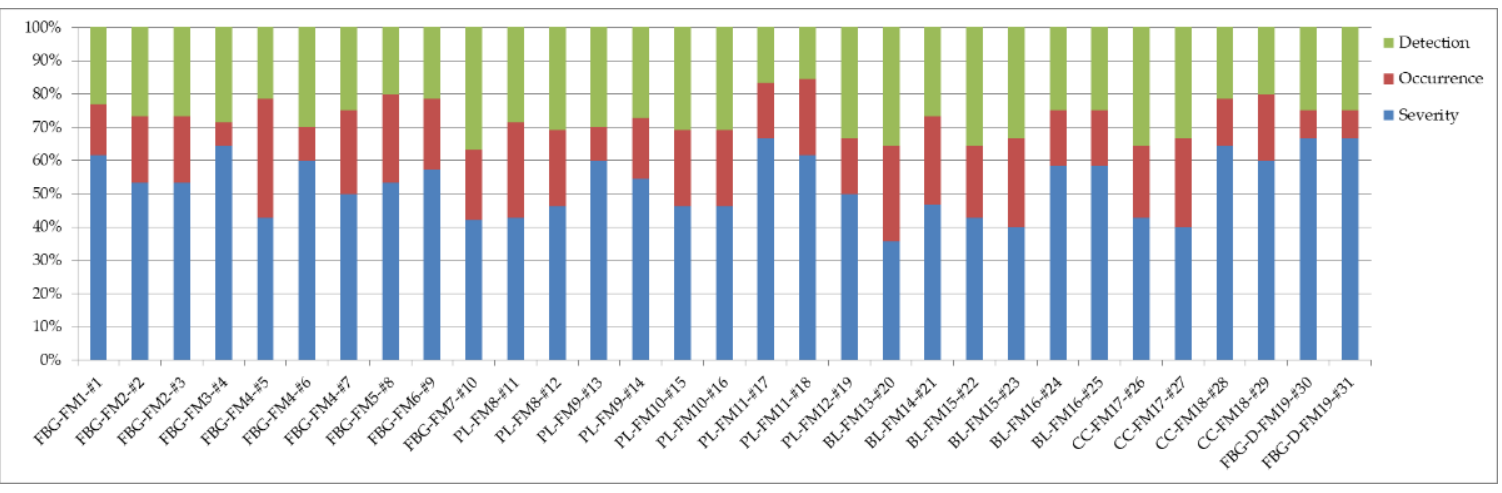

Figure 8. The RPN of failure modes of CFRP-packaged FBG sensors.

Furthermore, critical failure modes of each subsystem are analyzed by computing the RPN share (Figure 9). For FBG sensors, most failure modes are related to specific installation operations, such as failure cause \#1-\#7; thus, a standardized operation process is necessary. Significantly, the failure mode FBG-FM7 has the highest RPN share (10.20\%), for it is directly related to measurement accuracy and is comprehensively affected by the packaging layer, bonding layer, and others; thus, periodical calibration is essential. It is noteworthy that the unusable FBG sensors (caused by \#1, \#4, \#8, \#9, \#28, and \#29) do not have a higher RPN share, and although unusable FBG sensors will cause a short data loss, it is easy for the failed FBG sensors to be immediately detected and replaced. The most concerning problem in the CFRP-packaged FBG sensors is the falling measurement accuracy caused by system performance degradation, especially the degradation of PL and BL. For PL, most failure modes happen in the later stage of WTB fatigue testing, and they are mainly caused by complex force conditions (see failure cause $\# 11, \# 12, \# 14, \# 15$, and \#17-\#19). The failure mode PL-FM8 (with a total of 7.65\% RPN shares) should be taken note of, for it is difficult to observe without the help of instruments. For BL, most failure modes are related to the bonding process (see failure cause \#21-\#24), which are manually operated. The adhesive types, the size of the bonding layer, the stress conditions during the fatigue test, etc., will affect the bonding performance. Though the influence of the bonding process on the measurement accuracy of FBG sensors has been studied previously $[8,10]$, a unified pasting process has not been formed at present. For CC, CC-FM17 (with a total of $9.56 \%$ RPN shares) is the main failure mode. It reduces the transmission distance and immediately affects the allowable number of FBG sensors on each channel. For FBG-D, its reliability is relatively high compared with other subsystems, as the FBG demodulator is a fairly mature product and it is placed indoors. 


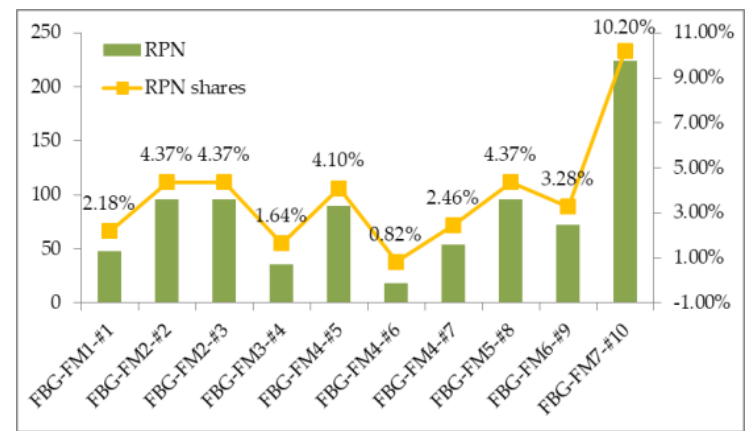

(a)

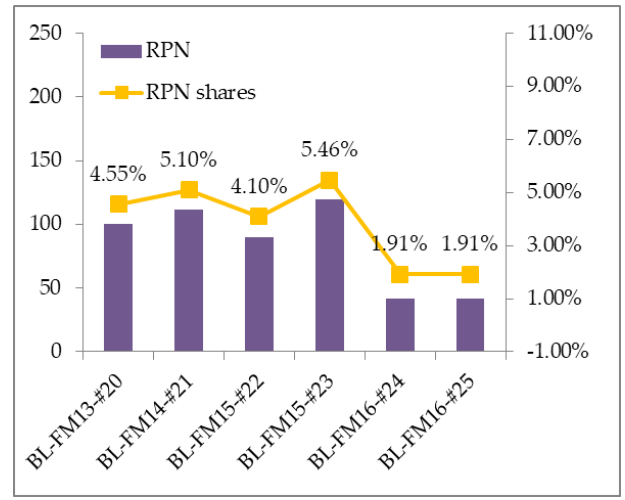

(c)

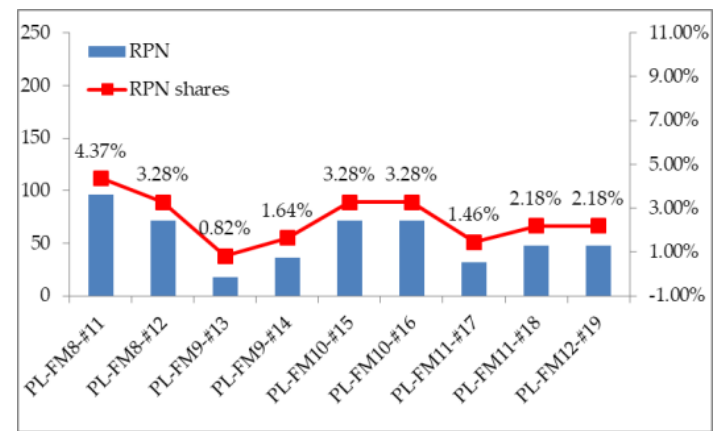

(b)

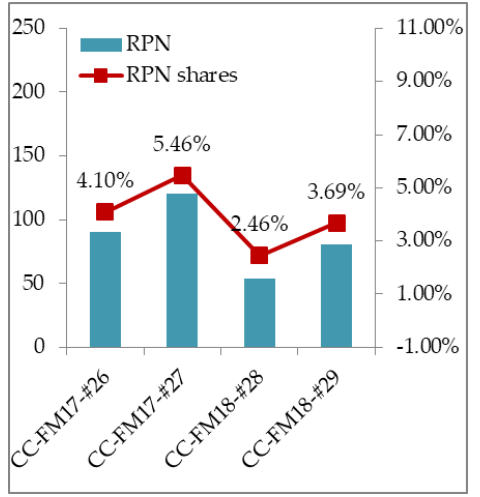

(d)

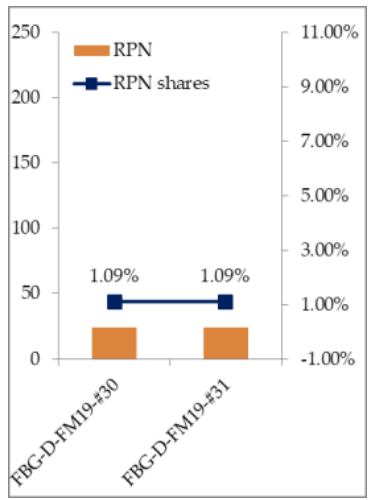

(e)

Figure 9. The RPN and RPN shares of each subsystem: (a) RPN and RPN shares of FBG failures; (b) RPN and RPN shares of PL failures; (c) RPN and RPN shares of BL failures; (d) RPN and RPN shares of CC failures; (e) RPN and RPN shares of FBG-D failures.

\section{Reliability Analysis of CFRP-Packaged FBG Sensors Using the FTA Technique}

\subsection{A Brief Introduction of the FTA Techique}

Fault tree analysis (FTA) takes the unexpected fault event (top event) of the system as the target, finds out all the direct and potential factors leading to the occurrence of the top event step by step, and builds the logical relationship between the system and the basic events into an inverted tree graph through the corresponding logic gate symbols [15-18]. The general FTA analysis process is shown in Figure 10.

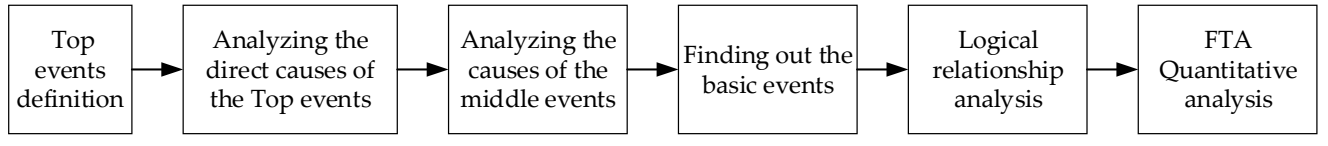

Figure 10. Flow chart of fault tree analysis.

\subsection{FTA of CFRP-Packaged FBG Sensors}

The failure modes with higher RPN are defined as the key faults [25]. According to Section 3, the 19 failure modes of CFRP-packaged FBG sensors are listed in descending order by their RPN shares (Figure 11). From Figure 11, it can be seen that the failure modes with the highest RPN share are "FBG-FM7 (with RPN share 10.20\%)", "BL-FM15 (with a total of $9.56 \%$ RPN shares)", and "CC-FM17 (with a total of 9.56\% RPN shares)". 


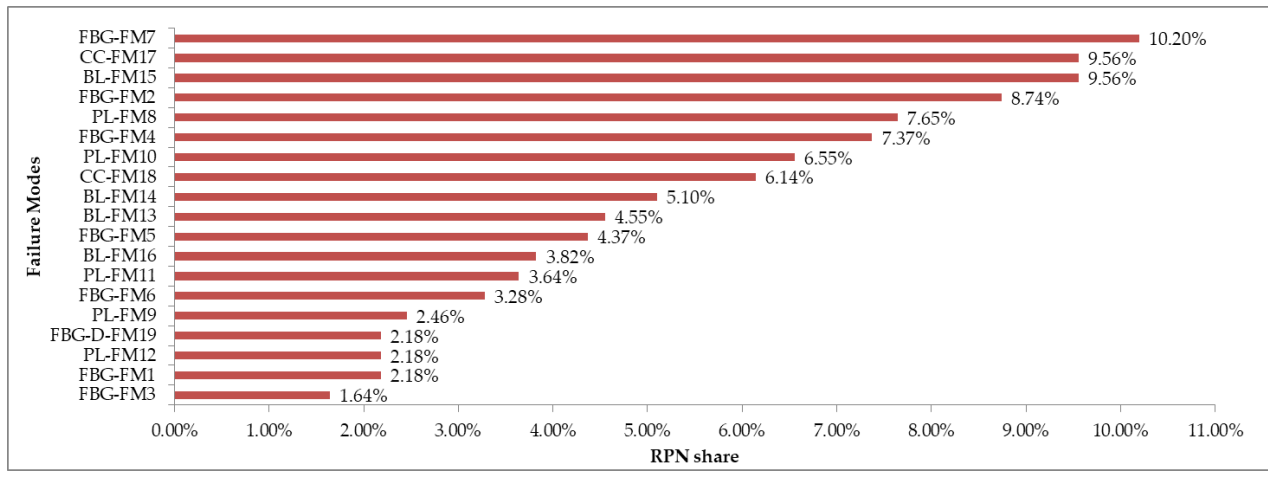

Figure 11. RPN shares of the 19 failure modes of CFRP-packaged FBG sensors.

The fault trees of the three key faults are established, as shown in Figure 12, and the detailed information of fault events in fault trees is shown in Table 4.

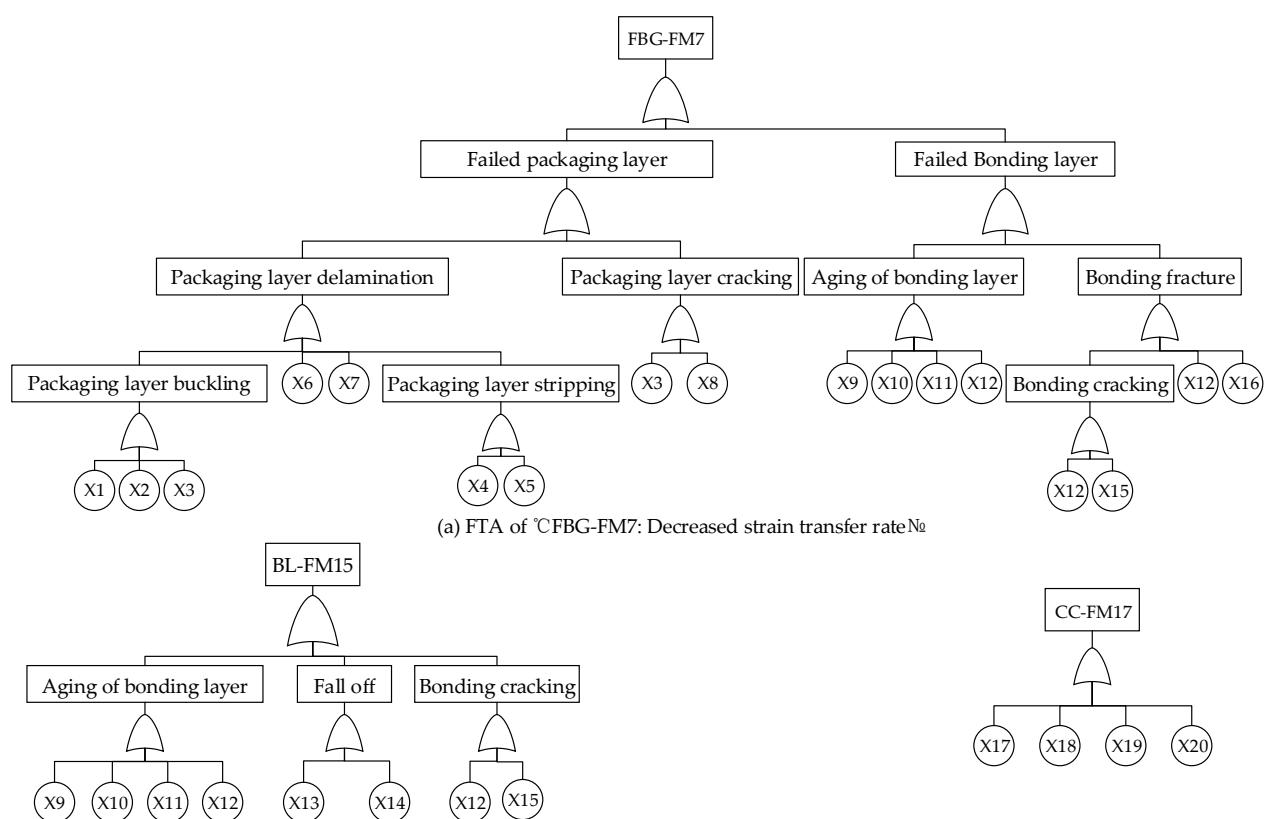

(b) FTA of ${ }^{\circ} \mathrm{CBL}-\mathrm{FM} 15$ : Decreased bonding performance of the bonding layer№

(c) FTA of ${ }^{\circ} \mathrm{CCC}-\mathrm{FM} 17$ : Power loss№

Figure 12. FTA of "FBG-FM7", "BL-FM15", and "CC-FM17".

Table 4. The detailed information of fault events in fault trees.

\begin{tabular}{|c|c|c|c|c|c|}
\hline No. & Basic Event & No. & Basic Event & No. & Basic Event \\
\hline $\mathrm{X} 1$ & $\begin{array}{l}\text { Too high temperature } \\
\text { in packaging process }\end{array}$ & $\mathrm{X} 8$ & Stress concentration & $\mathrm{X} 15$ & $\begin{array}{l}\text { Unsuitable curing } \\
\text { temperature }\end{array}$ \\
\hline $\mathrm{X} 2$ & $\begin{array}{l}\text { Excessive pressure in } \\
\text { packaging process }\end{array}$ & X9 & Affected by temperature & $\mathrm{X} 16$ & $\begin{array}{l}\text { Stress concentration in } \\
\text { bonding layer }\end{array}$ \\
\hline $\mathrm{X} 3$ & $\begin{array}{c}\text { Asymmetric CFRP } \\
\text { layers }\end{array}$ & $\mathrm{X} 10$ & $\begin{array}{l}\text { Temperature-moisture } \\
\text { coupling environment }\end{array}$ & $\mathrm{X} 17$ & $\begin{array}{l}\text { Mismatch structure } \\
\text { parameters }\end{array}$ \\
\hline $\mathrm{X} 4$ & $\begin{array}{l}\text { Stress concentration at } \\
\text { the changing section }\end{array}$ & $\mathrm{X} 11$ & $\begin{array}{c}\text { Affected by alternating } \\
\text { load }\end{array}$ & $\mathrm{X} 18$ & Fiber bending loss \\
\hline$\times 5$ & $\begin{array}{l}\text { Excessive load in } \\
\text { packaging process }\end{array}$ & $\mathrm{X} 12$ & $\begin{array}{c}\text { Residual internal stress in } \\
\text { bonding layer }\end{array}$ & X19 & \multirow{3}{*}{$\begin{array}{c}\text { Rayleigh scattering } \\
\text { loss } \\
\text { light wave absorption } \\
\text { loss }\end{array}$} \\
\hline $\mathrm{X} 6$ & Under impact force & $\mathrm{X} 13$ & Small bonding thickness & $\mathrm{X} 20$ & \\
\hline$X 7$ & Interlamination Stress & $\mathrm{X} 14$ & Poor bonding materials & & \\
\hline
\end{tabular}




\subsection{Results and Discussion}

By analyzing the minimum cut sets of each fault tree, we can ascertain the weak links of the system. In this paper, the minimum cut sets of each fault tree are obtained using the descending method, as shown in Table 5.

Table 5. The minimum cut sets of each key fault.

\begin{tabular}{cc}
\hline Top Events & Minimum Cut Sets \\
\hline FBG-FM7: Decreased strain transfer rate & 14 \\
BL-FM15: Decreased bonding performance of & 7 \\
the bonding layer & 4 \\
CC-FM17: Power loss & 4 \\
\hline
\end{tabular}

The failure probabilities of each fault event are given according to the WTB's field tests, laboratory tests, laboratory simulation test, and expert opinion (Table 6).

Table 6. Failure probability of each basic event.

\begin{tabular}{cccccccc}
\hline No. & $\begin{array}{c}\text { Failure } \\
\text { Probability }\end{array}$ & No. & $\begin{array}{c}\text { Failure } \\
\text { Probability }\end{array}$ & No. & $\begin{array}{c}\text { Failure } \\
\text { Probability }\end{array}$ & No. & $\begin{array}{c}\text { Failure } \\
\text { Probability }\end{array}$ \\
\hline X1 & $4 \times 10^{-4}$ & X6 & $10^{-2}$ & X11 & $10^{-2}$ & $X 16$ & $2 \times 10^{-3}$ \\
X2 & $4 \times 10^{-4}$ & X7 & $10^{-2}$ & X12 & $2 \times 10^{-3}$ & $X 17$ & $4 \times 10^{-4}$ \\
X3 & $4 \times 10^{-4}$ & X8 & $4 \times 10^{-4}$ & X13 & $2 \times 10^{-3}$ & $X 18$ & $10^{-2}$ \\
X4 & $10^{-2}$ & X9 & $4 \times 10^{-4}$ & X14 & $2 \times 10^{-3}$ & X19 & $2 \times 10^{-3}$ \\
X5 & $4 \times 10^{-4}$ & X10 & $10^{-2}$ & X15 & $10^{-2}$ & $X 20$ & $2 \times 10^{-3}$ \\
\hline
\end{tabular}

Without considering the correlation between basic events, the failure probability of the three top events can be calculated:

$$
\begin{aligned}
& P(T)=P\left(K_{1} \cup K_{2} \cup \cdots \cup K_{r}\right) \\
& =\sum_{i=1}^{r} P\left(K_{i}\right)-\sum_{i<j=2}^{r} P\left(K_{i} K_{j}\right)+\sum_{i<j<k=3}^{r} P\left(K_{i} K_{j} K_{j}\right)+\cdots+(-1)^{r-1} P\left(K_{1} K_{2} \cdots K_{r}\right) \\
& \approx \sum_{i=1}^{r} P\left(K_{i}\right)
\end{aligned}
$$

where $K_{i}, K_{j}, K_{j}$ are the $i$-th, $j$-th, and $k$-th minimum cut sets, respectively, and $r$ is the number of the minimum cut set. Thus, the failure probabilities of "FBG-FM7", "BL-FM15", and "CC-FM17" are 0.06242, 0.03554, and 0.01398, respectively.

The property weightiness of basic events in each FTA can be calculated:

$$
\Delta g_{i}(t)=\frac{\partial F_{s}(t)}{\partial F_{i}(t)}
$$

where $F_{S}(t), F_{i}(t)$ are the failure probability of the top event and the basic event, respectively. The property weightiness of basic events in FTAs of "FBG-FM7", "BL-FM15", and "CCFM17" are shown in Figure 13. From Figure 13, we can infer that the property weightiness of all basic events are approximately equivalent. The reason is related to the production and arrangement process of the CFRP-packaged FBG sensors, which are mainly manually operated without unified standards. In addition, the key faults of "FBG-FM7", "BL-FM15", and "CC-FM17" are mainly caused by the manufacturing process (see X1-X3, X6, X9, $\mathrm{X} 10$, etc.) and stress conditions (X4-X6, X7, X8, etc.); thus, further study on the standard manufacturing process, the periodic quality testing of the $\mathrm{PL}, \mathrm{BL}$, and $\mathrm{CC}$, and the routine calibration of FBG sensors is important. 


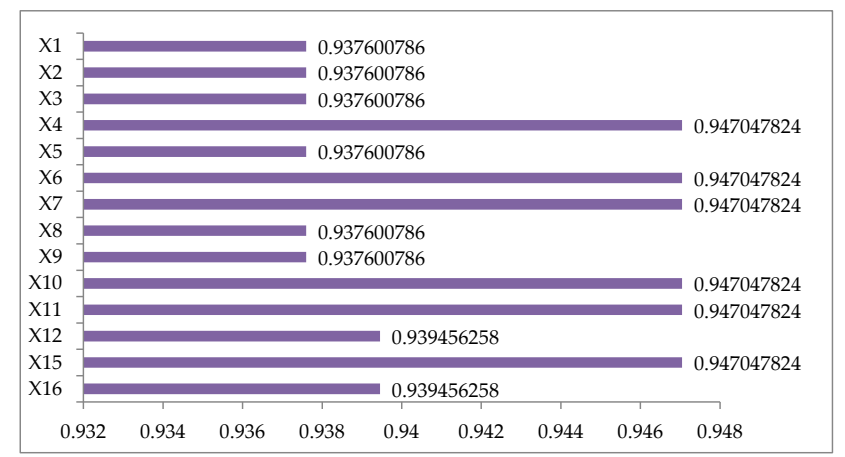

(a) The property weightiness of basic events in ${ }^{\circ}$ CFTA-FBG-FM7№

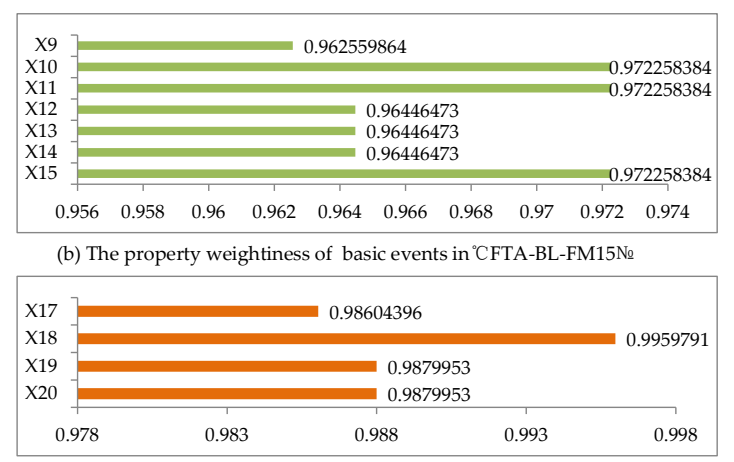

(c) The property weightiness of basic events in ${ }^{\circ}$ CFTA-CC-FM17№

Figure 13. The property weightiness of basic events in FTAs of "FBG-FM7", "BL-FM15", and "CC-FM17".

\section{Conclusions}

CFRP-packaged FBG sensors are widely used in WTB full-scale structural testing, and their quality and reliability have attracted a lot of attention. In this paper, FMEA and FTA techniques are used to complete the reliability analysis of CFRP-packaged FBG sensors. The failure modes, failure causes, and failure effects are analyzed for each of the FBG sensors, PL, BL, CC, and the FBG demodulator. The three key faults ("FBG-FM7", "BL-FM15", and "CC-FM17") are defined and their corresponding FTAs are built. Recommendations to mitigate the identified key failures are discussed. However, the FMEA and FTA methods used in this paper are based on precise probability theory without considering cognitive uncertainty, such as the assessment of severity (S), occurrence (O), and detection (D), or the definition of system or component failures, etc. Specifically, the RPN calculation method in this paper does not consider the weight of each index. Thus, in the future, other alternative methods for risk evaluation such as action priority $[13,18]$, fuzzy sets $[25,26]$, Bayesian network [26,27], interval analysis [28], etc., will be implemented.

Author Contributions: Conceptualization, Z.L. (Zheng Liu), Y.L., N.Z., Z.L. (Zhongwei Liang) and F.L.; methodology, Z.L. (Zheng Liu) and Y.L.; software, Z.L. (Zheng Liu) and Y.L.; validation, N.Z., Z.L. (Zhongwei Liang) and F.L.; investigation, Y.L.; data curation, Y.L.; writing—original draft preparation, Y.L.; writing-review and editing, Z.L. (Zhongwei Liang) and F.L.; supervision, Z.L. (Zheng Liu); project administration, Z.L. (Zhongwei Liang); funding acquisition, Z.L. (Zheng Liu) and Z.L. (Zhongwei Liang). All authors have read and agreed to the published version of the manuscript.

Funding: This research was funded by National Natural Science Foundation of China, grant number 51905116; National Key R\&D Program of China, grant number 2018YFB1501200, and National Key R\&D Program of China, grant number 2018YFB2000501.

Acknowledgments: The paper was partially supported by the National Natural Science Foundation of China (51905116), the National Key R\&D Program of China (2018YFB1501200), and the National Key R\&D Program of China (2018YFB2000501).

Conflicts of Interest: The authors declare no conflict of interest.

\section{References}

1. Zhou, H.F.; Dou, H.Y.; Qin, L.Z.; Chen, Y.; Ni, Y.Q.; Ko, J.M. A review of full-scale structural testing of wind turbine blades. Renew. Sustain. Energy Rev. 2014, 33, 177-187. [CrossRef]

2. Li, H.; Guedes Soares, C.; Huang, H.Z. Reliability analysis of floating offshore wind turbine using Bayesian Networks. Ocean. Eng. 2020, 217, 107827. [CrossRef]

3. International Standard IEC61400-23 Wind Turbines-Part 23: Full-Scale Structural Testing of Rotor Blades; International Electrotechnical Commission: Geneva, Switzerland, 2014.

4. GB/T 25384-2010: Full Scale Structural Test of Wind Turbine Blade; Standards Press of China: Beijing, China, 2010.

5. Arsenault, T.J.; Achuthan, A.; Coppotelli, G.; Grappasonni, C. Development of a FBG based distributed strain sensor system for wind turbine structural health monitoring. Smart Mater. Struct. 2013, 22, 075027. [CrossRef]

6. Tian, S.; Yang, Z.; Chen, X.; Xie, Y. Damage detection based on static strain responses using FBG in a wind turbine blade. Sensors 2015, 15, 19992-20005. [CrossRef] [PubMed] 
7. Wen, C.J.; Li, Y.L.; Wang, Y.B. High temperature failure and spectral characteristics of metallized fiber grating. Laser Infrared 2016, 46, 481-485.

8. Liu, H. Study on the Repeatability, Ronsistency and Fatigue Properties of Adhesive Packaged FBG Strain Sensors. Ph.D. Thesis, Wuhan University of Technology, Wuhan, China, 2014.

9. Zhang, W. Research on Key Technologies of reliability of FBG strain sensing system. Ph.D. Thesis, Chongqing University, Chongqing, China, 2016.

10. Liu, Z.; Liu, X.; Zhu, S.P.; Zhu, P.; Liu, W.; Correia, J.A.; De Jesus, A.M. Reliability assessment of measurement accuracy for FBG sensors used in structural tests of the wind turbine blades based on strain transfer laws. Eng. Fail. Anal. 2020, 112, 104506. [CrossRef]

11. IEC. Analysis Techniques for System Reliability_Procedure for Failure Mode and Effects Analysis (FMEA) (IEC 60812); International Electrotechnical Commission: Geneva, Switzerland, 2006.

12. Li, H.; Teixeira, A.P.; Guedes Soares, C. A two-stage Failure Mode and Effect Analysis of offshore wind turbines. Renew. Energy 2020, 162, 1438-1461.

13. Xiao, N.; Huang, H.Z.; Li, Y.; He, L.; Jin, T. Multiple failure modes analysis and weighted risk priority number evaluation in FMEA. Eng. Fail. Anal. 2011, 18, 1162-1170.

14. Yang, J.; Huang, H.Z.; He, L.P.; Zhu, S.P.; Wen, D. Risk evaluation in failure mode and effects analysis of aircraft turbine rotor blades using Dempster-Shafer evidence theory under uncertainty. Eng. Fail. Anal. 2011, 18, 2084-2092.

15. Kabir, S. An overview of fault tree analysis and its application in model based dependability analysis. Expert Syst. Appl. 2017, 77, 114-135. [CrossRef]

16. Huang, H.Z.; Zhang, H.; Li, Y.F. A new ordering method of basic events in fault tree analysis. Qual. Reliab. Eng. Int. 2012, 28, 297-305. [CrossRef]

17. Li, Y.F.; Mi, J.; Liu, Y.U.; Yang, Y.J.; Huang, H.Z. Dynamic fault tree analysis based on continuous-time Bayesian networks under fuzzy numbers. Proc. Inst. Mech. Eng. Part O J. Risk Reliab. 2015, 229, 530-541. [CrossRef]

18. Li, H.; Díaz, H.; Guedes Soares, C. A failure analysis of floating offshore wind turbines using AHP-FMEA methodology. Ocean. Eng. 2021, 234, 109261. [CrossRef]

19. Liu, J.; Chen, T.; Zhang, Y.; Wen, G.; Qing, Q.; Wang, H.; Sedaghati, R.; Xie, Y.M. On sound insulation of pyramidal lattice sandwich structure. Compos. Struct. 2019, 208, 385-394. [CrossRef]

20. Li, H.; Díaz, H.; Guedes Soares, C. A developed failure mode and effect analysis for floating offshore wind turbine support structures. Renew. Energy 2021, 164, 133-145. [CrossRef]

21. Knežević, V.; Orović, J.; Stazić, L.; Čulin, J. Fault tree analysis and failure diagnosis of marine diesel engine turbocharger system. J. Mar. Sci. Eng. 2020, 8, 1004. [CrossRef]

22. More, A.S.; Lad, P.S.; Krishnan, S.R.; Bhosale, S.R. Performance analysis of Strain sensor based on Fiber Bragg Grating. ITM Web Conf. 2020, 32, 02006. [CrossRef]

23. Karatas, C.; Degerliyurt, B.; Yaman, Y.; Sahin, M. Fibre Bragg grating sensor applications for structural health monitoring. Aircr. Eng. Aerosp. Technol. 2019, 92, 355-367. [CrossRef]

24. Kim, S.W. Characteristics of strain transfer and the reflected spectrum of a metal-coated fiber Bragg grating sensor. Opt. Lasers Eng. 2017, 96, 83-93. [CrossRef]

25. Huang, H.Z.; Tong, X.; Zuo, M.J. Posbist fault tree analysis of coherent systems. Reliab. Eng. Syst. Saf. 2004, 84, 141-148. [CrossRef]

26. Li, Y.F.; Huang, H.Z.; Mi, J.; Peng, W.; Han, X. Reliability analysis of multi-state systems with common cause failures based on Bayesian network and fuzzy probability. Ann. Oper. Res. 2019. [CrossRef]

27. Li, Y.F.; Liu, Y.; Huang, T.; Huang, H.Z.; Mi, J. Reliability assessment for systems suffering common cause failure based on Bayesian networks and proportional hazards model. Qual. Reliab. Eng. Int. 2020, 36, 2509-2520. [CrossRef]

28. Mi, J.; Li, Y.F.; Peng, W.; Huang, H.Z. Reliability analysis of complex multi-state system with common cause failure based on evidential networks. Reliab. Eng. Syst. Saf. 2018, 174, 71-81. [CrossRef] 